\title{
LA LIBERTAD EN PEDRO ABELARDO
}

\author{
César Raña Dafonte \\ Universidad de Santiago de Compostela
}

«Liber quippe est, quem timor ad serviendum non cogit, sed ad obediendum amor spontaneum facit»

(P. Abaelardus, Sermo-V, PL, 178, 421B)

\section{RESUMEN}

Pedro Abelardo es un autor muy original en el siglo XII. La originalidad se aprecia especialmente en el tema de la libertad o libre albedrío. Es lo que ponemos de manifiesto en el presente trabajo.

Palabras Clave: Abelardo, originalidad, siglo XII, libertad, libre albedrío.

\begin{abstract}
Peter Abaelard is a very original author of the XII century. His originality especially made explicit in his treatment of the topic of liberty or free will. That is what is shown in this paper.
\end{abstract}

Key Words: Peter Abaelard, originality, XII century, liberty, free will.

A Pedro Abelardo, y su doctrina sobre la libertad humana, hay que encuadrarlo en la tradición agustiniana del pensamiento en la Alta Edad Media; pero también Aristóteles, transmitido por Boecio, influye en él considerablemente. No en vano le llamaban Peripateticus Palatinus. No obstante, debido a su talante creador, la aportación abelardiana resulta original, innovadora. Dado el horizonte agustiniano y aristotélicoboeciano en que se mueve, recojo a título de suave pincelada alguna información significativa de esta tradición, relativa a la libertad. En primer lugar un texto muy elocuente de San Agustín:

«Y no se crea que no tendrán libre albedrío los bienaventurados porque no podrán deleitarse en los pecados. Serán tanto más libres cuanto más libres se vean del placer de pecar hasta conseguir el placer indeclinable de no pecar. El primer libre albedrío que se dio al hombre cuando Dios lo creó recto, consistía en poder no pecar; pero podía también pecar. El último será superior a aquél y consistirá en no poder pecar. Y éste será también don de Dios, no posibilidad de su naturaleza. Porque una cosa es ser Dios, y otra, ser participante de Dios. Dios, por naturaleza, no puede pecar; en cambio, el que participa de Dios sólo recibe de El la gracia de no poder pecar. Guardar esta gradación es propio del don divino: dar primero un libre albedrío por el que el hombre pudiera no pecar $\mathrm{y}$, al fin, otro por el que no pudiera pecar. El primero permitía la adquisición de mérito, y el último, la recepción de premios. Mas, porque esta naturaleza pecó cuando podía pecar, es librada por una gracia más generosa para llegar a la libertad en que no pueda pecar. Así como la primera inmortalidad, que Adán perdió pecando, consistió en poder no morir, y la última consistirá en no poder morir, así el primer libre albedrío consistió 
en poder no pecar, y el último consistirá en no poder pecar. La voluntad de piedad y de equidad será tan inamisible como la felicidad. Es cierto que al pecar no conservamos ni la piedad ni la felicidad; empero, el querer la felicidad no lo perdimos ni cuando perdimos la felicidad. ¿Hemos de negar a Dios libre albedrío porque no puede pecar? Todos los miembros de la Ciudad santa tendrán una voluntad libre, exenta de todo mal y llena de todo bien, gozando indeficientemente de la jocundidad de los goces eternos, olvidada de las culpas y de las penas, pero sin olvidarse de su liberación para no ser ingrata con su libertadons ${ }^{1}$.

En este texto están consignadas las principales ideas agustinianas sobre nuestro tema. Distingue entre liberum arbitrium, como capacidad de autodeterminación, y libertas (vera), como orientación al bien. La alternativa negativa (autodeterminación al mal) sería una libertas falsa.

Un eslabón fundamental en la tradición agustiniana, y en este caso, sobre todo, de la tradición aristotélica altomedieval, es Boecio, cuya influencia en Pedro Abelardo es muy acentuada. Por ello señalo como de especial interés en el tema que nos ocupa un famoso texto del Comentario al Perihermeneias de Aristóteles que condensa su visión sobre el libre albedrío. Lo recogerá con gran insistencia Pedro Abelardo, como veremos.

Escribe Boecio:

«Nosotros, pues, sostenemos que el libre albedrío se manifiesta cuando algo que debemos de hacer u omitir es fruto de nuestra reflexión y ponderación, sin nada exterior que nos determine: llegamos a realizar una acción y consumarla después de pensarlo previamente, de forma que lo que hacemos tenga su origen en nuestra reflexión, no habiendo nada que desde fuera y con violencia nos determine o impida [...]. Nosotros, en cambio, no defendemos que el libre albedrío de la voluntad es aquello que uno quiere [apetece], sino lo que haya decidido después de reflexionar y sopesar las razones. De otra manera, también muchos animales tendrian libre albedrío de la voluntad. En efecto, observamos que buscan espontáneamente algunas cosas y huyen espontáneamente de otras. Porque, si querer [apetecer] algo o rechazarlo lo consideramos como el nombre adecuado de libre albedrío, éste no sería exclusivo del ser humano, sino también de los demás animales, en los que nadie duda que tal poder de libre albedrío no existe: es, pues, para nosotros el libre albedrio un juicio libre acerca de la voluntad, como indican los mismos términos. Así, siempre que surgen imágenes en nuestro ánimo y provocan la voluntad [el deseo], la razón las sopesa, y juzga acerca de ellas, y realiza lo que considera mejor, después de ponderar con deliberación y decidir con reflexión; ỳ por ello algunas cosas atractivas y con apariencia de utilidad las despreciamos, y otras desagradables, aunque molestas, las buscamos con afán. Por tanto, no en la voluntad, sino en el juicio sobre la voluntad con-

1 San Agustín, «De civitate Dei», XXII, 30, 3, en Obras de San Agustín, BAC, Madrid, 1965 (bilingüe), vol. 17, pp. 775-776. («Nec ideo liberum arbitrium non habebunt, quia peccata eos delectare non poterunt. Magis quippe erit liberum, a delectatione peccandi usque ad delectationem non peccandi indeclinabilem liberatum. Nam primum liberum arbitrium, quod homini datum est, quando primum creatus est rectus, potuit non peccare, sed potuit et peccare: hoc autem novissimum eo potentius erit, quo peccare non poterit. Verum hoc quoque Dei munere, non suae possibilitate naturae. Aliud est enim, esse Deum; aliud, participem Dei. Deus natura peccare non potest; particeps vero Dei ab illo accipit, ut peccare non possit. Servandi autem gradus erant divini muneris, ut primum daretur liberum arbitrium, quo non peccare posset homo; novissimum, quo peccare non posset: atque illud ad comparandum meritum, hoc ad recipiendum praemium pertineret. Sed quia peccavit ista natura cum peccare potuit, largiore gratia liberatur, ut ad eam perducatur libertatem, in qua peccare non possuit. Sicut enim prima immortalitas fuit, quam peccando Adam perdidit, posse non mori, novissima erit non posse mori: ita primum liberum arbitrium posse non peccare, novissimum non posse peccare. Sic enim erit inamissibilis voluntas pietatis et aequitatis, quomodo est felicitatis. Nam utique peccando nec pietatem nec felicitatem tenuimus, voluntatem vero felicitatis nec perdita felicitate perdidimus. Certe Deus ipse numquid, quoniam peccare non potest, ideo liberum arbitrium habere negandus est? Erit ergo illius civitatis et una in omnibus, et inseparabilis in singulis voluntas libera, ab omni malo liberata, et impleta omni bono, fruens indeficienter aeternorum iucunditate gaudiorum, oblita culparum, oblita poenarum; nec tamen ideo suae liberationis oblita, ut liberatori suo non sit grata»). 
siste el libre albedrí; y no en la imaginación, sino en el examen diligente sobre la misma imaginación, y por eso nosotros mismos rechazamos los principios [impulsos, inclinaciones] de ciertas acciones. Esto es, sin duda, usar de la razón, usar de la reflexión. El existir, en efecto, es común en nosotros con los demás animales, sólo nos distinguimos por la razón. Y, si sólo por la razón somos distintos de los otros animales, ¿por qué dudamos que usar de la razón es lo mismo que usar de la reflexión? Porque, si alguien no es reflexivo, elimina la razón del hombre, y eliminada la razón del ser humano, ni siquiera pervivirá la humanidad $»^{2}$.

\author{
Es significativa la insistencia en la racionalidad como raíz de la libertad en la referencia \\ boeciana. \\ Otro de los transmisores de la tradición agustiniana hasta el siglo XII es, sin duda, San An- \\ selmo. En breves palabras nos presenta su visión de la libertad:
}

$\ll D$-- Si no se hubiera dado a esta naturaleza la libertad para que observara la rectitud de la voluntad por sí misma, no tendría valor desde el punto de vista de la justicia, puesto que es claro que la justicia es la rectitud de la voluntad observada por si misma, y creemos que el libre albedrío está ordenado a la justicia. Por lo cual hay que afirmar, como cosa cierta, que la naturaleza racional no la ha recibido más que para guardar la rectitud de la voluntad por sí misma.

$M$.- Por consiguiente, puesto que toda libertad es poder, este libre albedrío es el poder de observar la rectitud de la voluntad por sí misma.

D.- No puede ser otra cosa. [...]

D. - Para terminar hay que dividir, finalmente, esta libertad, porque, aunque tal como la has definido sea común a todas las criaturas racionales, la de Dios difiere mucho de la de las criaturas racionales, y ésta a su vez es muy diversa.

M.- Existe el libre albedrío que es $a$ se, no ha sido creado ni recibido de un donante, y que no pertenece más que a Dios solo, y el libre albedrío creado y dado por Dios, que es el de los ángeles y de los hombres. Creado o recibido, difiere según que tiene que conservar la rectitud o carece de ella. El que lo posea, se halla unido a ella inseparablemente o no. El libre albedrío que no está unido a ella inseparablemente, es el de todos los ángeles antes de la caída de los malos y la confirmación de los buenos; es también el de todos los hombres que poseen la rectitud antes de su muerte. El que se halla unido inseparablemente a la rectitud, es el de los elegidos, ángeles y hombres, pero de los ángeles elegidos después de la ruina de los réprobos y de los hombres elegidos después de su muerte.

2 Boecio, In De interpretatione, PL, 64, 492B-493A. («Nos enim liberum arbitrium ponimus, nullo extrinsecus cogente in id quod nobis faciendum, vel non faciendum judicantibus perpendentibusque videatur, ad quam rem praesumpta prius cogitatione perficiendam et agendam venimus, ut et id quod fit, ex nobis et ex nostro judicio principium sumat, nullo extrinsecus aut violenter cogente, aut violenter impediente. [...]. Nos autem liberum voluntatis arbitrium non id dicimus quod quisque voluerit, sed quod quisque judicio et examinatione collegerit. Alioqui multa quoque animalia habebunt liberum voluntatis arbitrium. Illa enim videmus sponte quaedam refugere, quibusdam sponte concurrere. Quod si velle aliquid vel nolle hoc recte liberi arbitrii vocabulo teneretur, non solum hoc esset hominum, sed caeterorum quoque animalium, quibus hanc liberi arbitrii potestatem abesse quis nesciat: sed est liberum arbitrium, quod ipsa quoque vocabula produnt, liberum nobis de voluntate judicium. Quotiescunque enim imaginationes quaedam concurrunt animo, et voluntatem irritant, eas ratio perpendit, et de his judicat, et quod ei melius videtur cum arbitrio perpenderit et judicatione collegerit, facit, atque ideo quaedam dulcia speciem utilitatis monstrantia spernimus, quaedam amara, licet nolentes, fortiter sustinemus. Ideo non in voluntate, sed in judicatione voluntatis liberum constat arbitrium, et non in imaginatione, sed in ipsius imaginationis perpensione consistit, atque ideo quarumdam actionum nos ipsi principia non sequaces sumus. Hoc est enim uti ratione, uti judicatione. Esse enim commune nobis est cum caeteris animanlibus sola ratione disjungimur. Quod si sola est judicatione inter nos et caetera animalia distantia, cur dubitemus ratione uti, hoc esse quod uti judicatione? Quam si quis ex rebus tollat, rationem hominis sustulit, hominis ratione sublata, nec ipsa quoque humanitas permanebit»). 
En cuanto al libre albedrío que carece de rectitud, puede carecer irreparablemente o no. Este último es de todos los hombres que carecen de ella solamente en esta vida, aunque algunos no la vuelven a encontrar nunca. La libertad absolutamente irrecuperable es la de los ángeles réprobos después de su caída y de los condenados después de la muerte.

D.- Tu definición y tu división de esta libertad me han dejado de tal modo satisfecho con la ayuda de Dios, que no puedo encontrar materia a una nueva pregunta ${ }^{3}$.

En esta alusión a la tradición, de que se nutre nuestro autor, se aprecia cómo recibe el tema de la libertad. Se cifra en la naturaleza humana y su peculiar rasgo de la racionalidad. Las referencias antropológicas y sociológicas son predominantemente a la naturaleza, a lo sumo a un grupo o estatus dentro de esa naturaleza: el justo, el pecador, el siervo, el noble, etc. Esto, como veremos, da un giro muy acentuado en el siglo XII y, precisamente, Pedro Abelardo es figura clave del nuevo sesgo en la concepción de la libertad, cifrada en la relevancia o predominio del individuo; todo ello está íntimamente ligado a su nominalismo contrapuesto al realismo de siglos anteriores (e incluso de su propio siglo).

Por eso, antes de centrarnos en el problema de la libertad en Abelardo conviene recordar el nuevo horizonte intelectual, y la concepción del individuo humano en el siglo XII. Con sólo hojear documentos de este siglo, inmediatamente captamos síntomas que nos instalan en algo novedoso. Un excepcional conocedor del siglo XII, J. Le Goff, con brevedad, pero con toda nitidez, nos sitúa en el nuevo horizonte:

«Desde Bernardo Silvestris a Alain de Lille, se desarrolla la tesis de la analogia entre el mundo y el hombre, entre el megacosmo y ese universo en miniatura que es el hombre [...]. Ese hombre microcosmos se encuentra, pues, colocado en el centro de un universo que él reproduce, está en armonía con ese universo, puede manejar sus hilos y se encuentra en estado de connivencia con el mundo. Así se le abren perspectivas infinitas que vulgariza un Honorio de Autun y tal vez más aún esa mujer extraordinaria, la abadesa Hildegarda de Bingen [...].

3 S. Anselmo, «De libertate arbitrii», en San Anselmo, Obras completas, Vol I, BAC, Madrid, 1952 (bilingüe), pp. 561, 587.

( $(D$. - Si non illa libertas data esset illi naturae ut voluntatis rectitudinem propter ipsam servaret rectitudinem, non valeret ad iustitiam; quoniam constat iustitiam esse rectidudinem voluntatis propter se servatam. Sed ad iustitiam prodesse arbitrii libertatem credimus. Quare indubitanter asserendum est rationalem naturam non eam accepisse nisi ad servandam rectitudinem voluntatis propter ipsam rectitudinem.

M.- Ergo quoniam omnis libertas est potestas, illa libertas arbitrii est potestas servandi rectitudinem voluntatis propter ipsam rectitudinem.

D.- Non potest aliud esse.

M. - Iam ergo clarum est liberum arbitrium non esse aliud quam arbitrium potens servare rectitudinem voluntatis propter ipsam rectitudinem [...].

D.- Restat nunc ut dividas eandem libertatem. Quamvis enim secundum hanc definitionem communis sit omni rationali naturae, multum tamen differt illa quae Dei est ab illis quae rationalis creaturae sunt, et illae ab invicem. $M$.- Libertas arbitrii alia est a se; quae nec facta est nec ab alio accepta, quae est solius Dei; alia a Deo facta et accepta, quae est angelorum et hominum. Facta autem sive accepta alia est habens rectitudinem quam servet, alia carens. Habens, alia tenet separabiliter, alia inseparabiliter. Illa quidem quae separabiliter tenet, fuit angelorum omnium, antequam boni confirmarentur et mali caderent; et est omnium hominum ante mortem, qui habent eandem rectitudinem. Quae vero tenet inseparabiliter, est electorum angelorum et hominum. Sed angelorum post ruinam reproborum, et hominum post mortem suam. Illa autem quae caret rectitudine, alia caret recuperatiliter, alia irrecuperabiliter. Quae recuperabiliter caret, est tantum in hac vita omnium hominum illa carentium, quamvis illam multi non recuperent. Quae autem irrecuperabiliter caret, est reproborum angelorum et hominum; sed angelorum post ruinam, et hominum post hanc vitam.

D.-De definitione et de divisione libertatis huius Deo annuente sic mihi satisfecisti, ut nihil queam invenire, quod necesse habeam de illis interrogare»). 
La última palabra de este humanismo declara sin duda que el hombre, que es naturaleza, que puede comprender la naturaleza por la razón, puede también transformarla mediante su actividad.

El intelectual del siglo XII, situado en el centro del taller urbano, ve el universo a imagen de ese taller, vasta fábrica en la que zumba el ruido de todos los oficios. La metáfora estoica del mundo fábrica es retomada en un medio más dinámico con mayor eficacia y alcance. [...].

En ese taller, el hombre se afirma como un artesano que transforma y crea. Redescubrimiento del homo faber, cooperador de la creación con Dios y con la naturaleza. - «Toda obra, dice Guillermo de Conches, es obra del Creador, obra de la naturaleza o del hombre artesano que imita la naturalezay.

Así se transforma también la imagen de la sociedad humana. Vista en esta perspectiva dinámica, que da su sentido a las estructuras económicas y sociales del siglo, esa imagen debe comprender a todos los trabajadores humanos. En esa rehabilitación del trabajo, los despreciados de ayer se integran en la ciudad humana, imagen de la ciudad divina. Juan de Salisbury en el Polycraticus restituye a la sociedad a los trabajadores rurales, «aquellos que trabajan en los campos, en los prados, en los huertos», y luego a los artesanos, «obreros de la lana, y todos los otros obreros mecánicos que trabajan la madera, el hierro, el bronce y los otros metales». En esta perspectiva el antiguo marco escolar de las siete artes liberales se desintegra. La nueva enseñanza debe dar su lugar no sólo a las nuevas disciplinas: la dialéctica, la física, la ética, sino también a las técnicas científicas y artesanales que constituyen una parte esencial de la actividad del hombre. En el programa de estudio de su Didascalion, Hugo de Saint-Víctor ratifica esta concepción nueva. Honorio de Autun la desarrolla en su famosa fórmula: «El exilio del hombre es la ignorancia; su patria es la ciencia». Y, en efecto, agrega: "Y se llega a ella mediante las artes liberales que son otras tantas ciudades etapas». La primera ciudad es la gramática, la segunda es la retórica, la tercera la dialéctica, la cuarta la aritmética, la quinta la música, la sexta la geometría, la séptima la astronomía. Hasta aquí todo es tradicional. Pero el camino no ha terminado. La octava es la fisica «en la cual Hipócrates enseña a los peregrinos las virtudes y la naturaleza de las hierbas, de los árboles, de los minerales, de los animales». La novena es la mecánica «en la que los peregrinos aprenden a trabajar los metales, la madera, el mármol, la pintura, la escultura y todas las artes manuales. Es allí donde Nemrod levantó su torre y donde Salomón construyó el templo. Es allí donde Noé construyó el arca, enseñó el arte de la fortificación y los diversos trabajos textiles». La décima es la economía: «Esta es la puerta de la patria del hombre. Alli se disponen los estados y las dignidades, se distinguen las funciones y los órdenes. Alli se les enseña a los hombres que se dirigen presurosos hacia su patria cómo alcanzar, según el orden de sus méritos, la jerarquía de los ángeles». De esta manera, con la política, termina la odisea del humanismo de los intelectuales del siglo XII ${ }^{4}$.

Estas palabras del medievalista francés resumen magistralmente el nuevo ambiente que se respira en el siglo XII, comparándolo con momentos anteriores del medievo. Conviene también subrayar la novedosa concepción de la realidad particular y del individuo humano, que se inicia y desarrolla a lo largo del siglo. En efecto, en torno al año 1100 comienza a resquebrajarse el rígido marco social del feudalismo, y la vida urbana va adquiriendo importancia. Además de los oratores, bellatores et laboratores surgirá la nueva clase de los burgueses (artesanos y mercaderes). Aparecen como el nuevo hombre libre. La conciencia de que el individuo, por su esfuerzo y por su dinero, puede sostenerse sin pertenecer a ninguna de las instituciones establecidas (Iglesia, Feudo) toma cuerpo y se desarrolla. Surgen las corporaciones o gremios de los distintos oficios, en los que cada individuo se va integrando libremente. En estas asociaciones se da una nueva relación de igualdad y libertad entre sus miembros, totalmente dis- 
tinta a la existente en el estado de vasallaje anterior. Por ello las consideraciones, que J. Burckhardt aplica al medievo en general, sólo son verdaderas hasta el siglo XII. Escribe lo siguiente: «Durante los tiempos medievales las dos caras de la conciencia (la que se enfrenta al mundo exterior y la que se relaciona con el hombre mismo) permanecian como cubiertas por un velo, soñando o en estado de duermevela. Este velo estaba tejido de fe, timidez infantil e ilusión; el mundo y la historia aparecían a través de él maravillosamente coloreados y el hombre se reconocía a sí mismo sólo como raza, pueblo, partido, corporación, familia u otra forma cualquiera de lo colectivo $)^{5}$. Decíamos anteriormente que estas apreciaciones sólo son adecuadas con anterioridad al siglo XII, pues a partir de entonces la conciencia del individuo, como capaz por sí mismo de sobrevivir y de cambiar las condiciones de vida en las que se encontraba, nace como una semilla que se desarrollará paulatinamente hasta nuestros días. C. Morris sitúa el descubrimiento del individuo en la Europa del siglo XII. Afirma que el cristianismo con la doctrina de la salvación individual fue el fermento del que pudo surgir la conciencia del individuo ${ }^{6}$.

La conciencia del yo, como individuo, va unida a un sentimiento de autoaprecio y de libertad personal que se manifiesta, a partir del siglo XII, en enfrentamientos con la institución de la Iglesia, que había llegado a ser el soporte fundamental del feudalismo. La lucha por las investiduras, los movimientos subversivos (cátaros, albigenses, goliardos, etc.) son pruebas de que la sociedad cerrada feudal había comenzado a resquebrajarse. En este contexto sociopolítico de la primera mitad del XII surge una nueva visión teórica que da la primacía a lo singular, en contraposición y pugna con la opinión tradicional que daba la primacía a lo universal ${ }^{7}$. Todo esto está claramente reflejado en las discusiones del gran problema filosófico que atraviesa todo el medievo y que en el siglo XII adquiere una apasionante vitalidad. Obviamente me estoy refiriendo al tema de los universales. El realismo, vigente en la Alta Edad Media, hasta bien entrado el siglo XII, era el sustento teórico del feudalismo. Precisamente para los realistas los universales eran las auténticas realidades, mientras que las cosas individuales tenían escaso peso ontológico. En consonancia con lo dicho, escribe aguda y acertadamente Anselmo Sanjuán:

«El realismo parecía también acorde con una sociedad estamental de rígida estratificación en la que ni pintura, ni escultura, ni la vida misma parecían interesarse por la persona concreta y sí por el «estatus social». Era este último el que imprimía carácter respecto a derechos, deberes y relaciones con el poder (Estado e Iglesia). Pintura y estatuaria representan al «siervo», al «clérigo» o al «caballero», En la vida religiosa y social lo importante era ser «cristiano», «judío» 0 «infiel». La categorización epistemológica y la social se correspondían y reforzaban mutuamente. Cuando a una abadesa alemana del S. XI se le preguntó por la rígida separación conventual de las novicias según su origen social, respondió del modo más natural que también en un establo se separan vacas, ovejas y caballos» ${ }^{8}$.

Precisamente en la primera mitad del siglo XII nos encontramos con una crítica muy severa del realismo, iniciada por el verbalista Roscelino de Compiègne ( $\dagger$ 1120), y llevada a su punto álgido por Pedro Abelardo ( $\uparrow 1142$ ). Con su nominalismo Abelardo y sus seguidores harán un cambio teórico de capital importancia. Podemos sintetizarlo en las siguientes afirmaciones: no existen realidades universales. Sólo hay cosas singulares. Los universales son meros nombres o conceptos elaborados por el entendimiento. En este contexto, y centrándo-

5 J. Burckhardt, La cultura del Renacimiento en ftalia, Barcelona, Emecé, 1971, p. 99.

6 Cfr. C. Morris, The discovery of the Individual 1050-1200, Univ. of Toronto Press, 1987.

7 En este apartado soy deudor del excelente trabajo del Prof. Antonio Pérez-Estévez, «El individuo en Duns Scoto», en Cuadernos Salmantinos de Filosofia, XXIII (1996) 87-146, especialmente, pp. 87-95.

8 Sanjuan, A. y Pujadas, M., «Introducción», en Pedro Abelardo, Diálogo entre un Filósofo, un Judío y un Cristiano, Yalde, Zaragoza, 1988, p. 52. 
nos en el ser humano, lo que importa es el individuo, su conciencia, su responsabilidad. El cambio es notorio. Aunque son primeros pasos, tendrán una proyección histórica enorme. En este sentido recojo de nuevo unas palabras muy acertadas del autor citado anteriormente:

«Anuladas las esencias específicảs o genéricas, el pensamiento abelardino se libera de la visión estereotipada de la realidad, dando relieve a lo inđ̣ividual y de modo especial en el caso de los hombres. Tanto en el plano moral como en el teológico acentúa el valor de la persona concreta, de su responsabilidad y de su conciencia [...].

Al rompercon el realismo, Abelardo negaba que el resultado de la abstracción fuese la posición de la esencia de las cosas en forma de imágenes mentales. Nuestras representaciones se enriquecen, no abstrayendo esencias acabadas y definidas, sino conociendo seres concretos y comparándolos entre sí. Así echa las bases para una epistemología empirista no dogmática que, muy desarrollada por Ockham, pasó a la modernidad y culminó en Locke y Hume»?.

El nominalismo de P. Abelardo tiene consecuencias en su antropología, así el comportamiento moral estará cifrado en la conciencia del individuo, es decir, el fundamento de la moralidad será el consentimiento personal y libre del individuo humano en su actuación. Todo lo que acabamos de relatar está latente también en la concepción abelardiana de la libertad.

\section{ABELARDO Y LA LIBERTAD, O LIBERTADES}

Después de la breve ambientación, ya nos adentramós en el tema de la libertad según el magister de Le Pallet. Primeramente nos fijamos en los aspectos más teóricos, para luego centrarnos en aplicaciones referentes a sectores de gran interés del comportamiento humano. Dado que nuestro autor destaca por sus cualidades didácticas, tanto en la docencia, como en sus escritos, seguiremos sus propias palabras con fidelidad.

Para captar el concepto de libertad, hemos de tener en cuenta su concepción del ser humano. Por decirlo en pocas palabras: Abelardo en su antropología recoge por una parte conceptos aristotélicos, transmitidos por Boecio; por otra, conceptos cristianos, sobre todo a través de San Agustín. Con estos materiales construye su dibujo del ser humano.

De inspiración aristotélicoboeciana es la definición de hombre, que relata en varios lugares, y la asume. En la Dialectica escribe: «Homo est animal rationale mortale» ${ }^{10}$, que reproduce casi literalmente lo que dice Boecio, entre otros lugares, en De consolatione philosophiae: «Homo est rationale animal atque mortale»" ${ }^{11}$. Recoge también de Boecio la explicación etimológica de hombre: «"Homo" ab "humo" nominatus est»12. Esta etimología subraya sólo un aspecto de la condición humana: la pertenencia a la tierra (al mundo); así aclara a continuación el pensador francés que el hombre no sólo está compuesto de tierra («quod quidem ex humo factus sit non solus»). Esto ya nos remite al segundo elemento constitutivo del ser humano, lo cual nos instala en la influencia agustiniana. No obstante en la noción filosófica ya quedaban consignados los dos componentes del ser humano: el cuerpo y el alma racional.

Bajo la influencia cristiano-agustiniana, Abelardo recuerda que el hombre se diferencia de los demás animales porque ha sido creado a imagen y semejanza del Creador. Así el distintivo específico de la naturaleza humana es ser portadora de la imagen de Dios. Esta

9 Sanjuan, A., Pujadas, M., «Introducción» (cit.), p. 54.

10 P. Abelardo, Dialectica, Assen, 1970, p. 51, líneas 17-18.

11 Boecio, De consolatione philosophiae, Libro I, prosa $6^{\mathrm{a}}$ (PL, 63, 653A).

12 Dialectica, (cit), p. 128, líneas 2-3. 
aportación teológica resalta la dignidad humana, al ser una imago Dei. Precisamente esta grandeza humana, es decir, el ser imagen de Dios, se debe a la racionalidad. En las consideraciones sobre la racionalidad humana hace ver cómo ésta remite al componente inmaterial del hombre: el alma. En estas consideracions antropológicas sobre la grandeza del ser humano apreciamos que Abelardo hace una síntesis armoniosa entre la concepción helénica y bíblica del hombre. Una de las derivaciones de la racionalidad humana será su responsabilidad moral y, como presupuesto esencial, (constitutivo de la moralidad) está la libertad. Por eso es normal que este concepto esté latente en todos sus discursós éticos. Precisamente el problema ético es una constante en nuestro autor. Por razones obvias no entro en este tema tan querido de Abelardo, aunque haremos alusión a él, por necesidad, en muchas referencias sobre la libertad ${ }^{13}$.

\section{El concepto de libertad o libre albedrío}

En distintos lugares de sus obras emerge el tema del libre albedrío, y su concepto. Voy a recoger los más significativos, siguiendo un orden cronológico aproximado.

a) En la Dialectica hace una primera alusión al concepto de libertad. Tiene in mente, sin la menor duda, a Boecio y su aportación sobre el libre albedrío:

«El libre albedrío, como indican los propios términos, es un juicio libre sobre la voluntad, por el que, cuando nos decidimos a la realización de una acción, lo hacemos después de la deliberación y decisión del ánimo, referente a si ha de ser realizada o no, y sin que ningún agente externo nos determine violentamente o impida violentamente la realización. Por tanto, según sostiene Boecio, el libre albedrío no se basa en la sola voluntad, sino también en el juicio de la mente. En efecto, siempre que se presentan imágenes al ánimo y provocan a la voluntad [apetito], la razón las sopesa, y decide lo que le parece más conveniente [mejor]. $\mathrm{Al}$ sopesar con el arbitrio y tomar la decisión, después realiza la acción; y por eso despreciamos cosas atractivas [seductoras] y con apariencia grata, y, por el contrario con gran fuerza nos decidimos por cosas dificiles que desagradan; por lo cual es manifiesto que el libre albedrío no se basa solamente en la voluntad, sino también en el juicio acerca de la voluntad. De no ser así los animales irracionales se diría que tienen libre albedrío, porque de modo espontáneo huyen de ciertas cosas, y de modo espontáneo apetecen otras» 14 .

Abelardo en esta referencia a Boecio está hablando como maestro de dialéctica, que fue su actividad inicial, por eso se centra en lo esencial, tratando de sintetizar y clarificar. Tal vez sea una de las primeras ocasiones en que afronta el tema del libre albedrío.

13 Para la visión ética de Abelardo, remito a sus obras: Etica y Diálogo entre un Filósofo, un Judío y un Cristiano. Merece también una mención muy destacada, para la visión ética de Abelardo el magnífico libro de Luis $\mathrm{E}$. Bacigalupo, Intención y conciencia en la Etica de Abelardo, Pontificia Univ. Católica del Perú, Fondo Editorial, 1992. En el presente artículo soy deudor sobre todo del Capítulo I: Felicidad y Libertad como Fundamentos de la Moral, pp. 51-108.

14 Abelardo, Dialectica, o. c., p. 215, líneas 15-28. («Liberum arbitrium est, ut ipsa indicia sunt vocabula, liberum de voluntate iudicium, ut cum ad aliquam rem perficiendam venimus, presumpta prius animi deliberatione et diiudicatione, utrum ea res sit facienda an non, nullo tamen extrinsecus violenter cogente aut violenter impediente. Non enim teste Boetio in sola voluntate liberum consistit arbitrium, sed etiam in iudicio mentis. Quotiens enim imaginationes animo concurrunt et voluntatem provocant, eas ratio perpendit, ac diiudicat quod melius sibi videtur. Cum arbitrio perpenderit et diiudicationem collegerit, tunc facit, atque ideo quedam dulcia et specie utilitatis auferentia spernimus, quedam amara licet nolentes, fortiter tamen sustinemus; usque adeo non in sola voluntate, sed in iudicio voluntatis liberum arbitrium consistit. Alioquin muta animalia, que sponte aliqua fugiunt, aliqua sponte appetunt, liberum arbitrium dicerentur habere»). 
En la etapa teológica, es decir, cuando ya había estudiado teología, cosa que realiza después de haber sido ya maestro de dialéctica, las polémicas intelectuales son mucho más agudas. En los escritos teológicos se aprecia un esmero especial y unas precauciones que, sin duda, son debidas a sus muchos y cualificados adversarios. Por ello los dos pasajes que voy a citar tienen gran interés y reflejan este ambiente.

b) En el:Commentarium super Epistolam ad Romanos se encuentra este precioso texto sobre el libre albedrío:

«En efecto, Boecio en el libro III de la segunda edición del Comentario al Perihermeneias, aclarando con esmero el concepto de libre albedrío, escribe: «nosotros, pues, sostenemos que el libre albedrío, no habiendo determinación externa alguna, consiste en que aquello que nos decidimos a realizar u omitir, es fruto de nuestra reflexión y decisión: a cuya realización llegamos después del previo conocimiento, de forma que lo que realizamos tome su principio de nuestra reflexión, y no haya nada que desde fuera nos determine violentamente». [Sigue diciendo]: «nosotros, en cambio, no sostenemos que el libre albedrío de la voluntad sea aquello que uno quiere [apetece], sino lo que haya decidido después de reflexionar y sopesar las razones. De otra manera, también muchos animales tendrían libre albedrío de la voluntad. Así, observamos que espontáneamente buscan algunas cosas, y huyen de otras. Porque si querer algo o rechazarlo lo consideramos como el nombre adecuado de libre albedrío, este no sería exclusivo del ser humano, sino también de los demás animales, en los cuales nadie duda que tal poder de libre albedrío no existe. Sin duda, como indican los propios términos, el libre albedrío es para nosotros un juicio libre sobre la voluntad. Así, siempre que surgen imágenes en nuestro ánimo y provocan a la voluntad, la razón las sopesa, y juzga acerca de ellas: y realiza lo que considera más oportuno, después de ponderar con decisión y decidir con reflexión. Y por ello algunas cosas atractivas y con apariencia de utilidad las despreciamos, y otras desagradables, aunque molestas, las buscamos con energía: de modo que no en la voluntad, sino en el juicio sobre la voluntad consiste el libre albedrío, y no en la imaginación, sino en el examen diligente sobre la misma imaginación. Y por ello nosotros mismos rechazamos las inclinaciones a ciertas acciones. Esto es, sin duda, usar de la razón, usar de la reflexión». De esta forma se deduce claramente de las citadas palabras de Boecio que el libre albedrío no es otra cosa que la misma facultad del ánimo para deliberar y decidir lo que quiere realizar, es decir, si ha de realizar o no lo que haya elegido» ${ }^{15}$.

En este segundo pasaje, Abelardo está hablando como teólogo. Toma todas las precauciones y garantías para poder enfrentarse a sus advesarios. Por eso ya no cita de memoria y ad sen-

15 Pedro Abelardo, «Comentarium super S. Pauli Epistolam ad Romanos», in Opera, Ed. De Victor Cousin, Vol. II, 1970, p. 239, líneas 10-34. («Boethius autem libro III editionis secundae in Perihermenias, quid sit liberum arbitrium diligenter aperiens ait: «Nos enim liberum arbitrium ponimus, nullo extrinsecus cogente, in id quod pro nobis faciendum vel non faciendum judicantibus perpendentibusque videatur: ad quam rem præsumpta prius cognitione perficiendam et agendam venimus, ut id quod sit ex nobis ex nostro principium judicio sumat, nullo extrinsecus aut violenter cogente aut impediente». Item: «Nos autem liberum voluntatis arbitrium non id dicimus quod quisque voluerit, sed quod quisque judicio et examinatione collegerit. Alioquin multa quoque animalia habebunt liberum voluntatis arbitrium. Illa enim videmus sponte quædam refugere, quibusdam sponte concurrere. Quod si velle aliquid vel nolle hoc recte liberi arbitrii vocabulo teneretur, non solum hoc esset hominis sed cæterorum quoque animalium, quibus hanc liberi arbitrii potestatem abesse quis nesciat? Sed est liberum arbitrium, quod ipsa quoque vocabula produnt, liberum nobis de voluntate judicium. Quotiescumque enim imaginationes animo concurrunt, et voluntatem irritant, eas ratio perpendit, et de his judicat: et quod ei melius videtur cum arbitrio perpenderit et judicatione collegerit, facit. Atque ideo quædam dulcia et speciem utilitatis monstrantia spernimus, quaedam amara licet nolentes, tamen fortiter sustinemus: adeo non in voluntate, sed in judicatione voluntatis liberum constat arbitrium, et non in imaginatione, sed in ipsius imaginationis perpensione conistit. Atque ideo quarundam actionum nos ipsi principia non sequances sumus. Hoc est enim uti ratione, uti judicatione». Ex his itaque verbis Boethii patet liberum arbitrium nihil aliud esse quam ipsam animi facultatem deliberandi ac dijudicandi id quod velit facere, an scilicet sit faciendum, an non quod elegerit sequendum»). 
sum a Boecio, sino con total rigor metodológico y a la letra. Por las palabras que sirven de apostilla a la cita no cabe duda de que comparte totalmente la visión del Romano sobre la libertad. Pero, antes de entrar en más consideraciones, reproduzco el tercer lugar anunciado.

c) En la Introductio ad Theologiam relata lo siguiente nuestro autor:

«Los filósofos, por el contrario, al definir el libre albedrío establecieron que es el libre juicio acerca de la voluntad. El arbitrio, sin duda, es la misma deliberación o decisión del ánimo, por la que alguien se propone hacer u omitir algo. Tal decisión es libre ciertamente, cuando no es forzada por una inclinación natural a aquello que se haya propuesto conseguir, sino que tiene en sưpoder de la misma manera tanto hacer lo que se propone como omitirlo. Por tanto donde no existe reflexión racional, por la que se pueda deliberar y decidir otra cosa, si ha de ser realizada o no; aunque estén en nuestro poder igualmente ambas opciones, de ninguna manera existe libre albedrío. Porque, aunque los animales irracionales puedan realizar algo u omitirlo por su voluntad [apetito]; sin embargo, como carecen de reflexión racional, no tienen libre albedrío. También si alguien quiere y dispone hacer una cosa, la cual no está en su poder, o que de la misma manera se realizaría sin su decisión, carecería de libre albedrío en lo que a esto refiere. Por ejemplo, con frecuencia nos proponemos hacer algo, que engañados [por equivocación] confiamos poder cumplir; y otras veces nos esforzamos o deseamos que se cumpla, lo que se realizaria igualmente sin nuestro propósito. Así; si algunos están obligados a morir con castigos duraderos, y deseen dar fin a los tormentos con la propia muerte, y se esfuerzan para ello, cuando esto sucede, de ningún modo lo logran desde su libre albedrío; porque evidentemente, aun sin ninguna premeditación, les sucedería lo mismo. Esta definición de libre albedrío ciertamente de ningún modo es aplicable a Dios, sino tan sólo a aquellos que tienen una voluntad mudable; y pueden optar por cosas contrarias; es decir, que esté en su poder que lo elegido pueda del mismo modo omitirlo o realizarlo. Por fin, también algunos redujeron a esto el libre albedrío: solamente se lo atribuyen a los que pueden hacer el bien y el mal. La opinión de estos también la sostiene San Jerónimo en su Homilia sobre el hijo pródigo; entre otras cosas, dice así: «Sólo Dios está libre de pecado; todos los demás, como poseen libre albedrío, pueden inclinar la voluntad a ambas partes». Ahora bien quien examine con minuciosidad el libre albedrío, a nadie que obra siempre el bien se lo niega; en grado máximo atribuyen el libre albedrío a Dios y a todos los confirmados en el bien, en la bienaventuranza, que ya no pueden caer en el pecado. Pues, cuanto más alguien se aleja del pecado, y cuanto más proclive es al bien; tanto más libre es su juicio para elegir el bien, cuanto más lejos esté de aquella última servidumbre del pecado, de la cual está escrito: «El que obra 'el pecado, es siervo del pecado» (Juan, VIII, 34). Por todo lo cual, como definición general y totalmente verdadera se dice que el libre albedrío se da cuando alguien que decide algo, como fruto de la reflexión, puede realizarlo voluntariamente y sin coacción. Sin duda, el libre albedrío, así entendido, lo posee indudablemente Dios y el hombre, es decir, todos los que no están privados de la facultad de la voluntad, pero especialmente, como dijimos, los que ya no pueden, de ninguna manera, pecar. Porque, aunque no pueden pecar, o de ningún modo puedan dejar de hacer el bien, porque no es lo conveniente; no por ello, sin embargo, realizan el bien por imposición [necesidad] de coacción alguna, porque ciertamente si no quisieran, de ningún modo serían obligados a hacerlo [...]. [Recordando a San Agustín]: «El primer libre albedrío consitía en poder no pecar, el último en no poder pecar» ${ }^{16}$.

16. P. Abelardo, «Introductio ad Thelogiam», en Opera (cit.), vol. II, pp. 139 (líneas 33-38)-I40 (líneas 1-33). («Liberum autem arbitrium definientes philosophi dixerunt, liberum de voluntate judicium. Arbitrium quippe est ipsa deliberatio sive dijudicatio animi, qua se aliquid facere vel dimittere quilibet proponit. Quæ tunc quidem dijudicatio libera est, cum ad hoc quod proposuerit exsequendum, nulla vi naturæ compellitur, sed æque in sua potestate habet tam illud facere quam dimittere. Ubi ergo ratio animi non est, per quam aliud deliberari possit et dijudicari, an faciendum sibi sit vel dimittendum, licet æque utrumque in nostra sit potestate, liberum nequaquam est arbitrium. Etsi enim bruta animalia quædam per voluntatem suam facere possunt vel dimittere; quia tamen judicio rationis 
Este tercer testimonio sobre la libertad tal vez sea posterior cronológicamente al del Comentario a la Epistola a los Romanos, porque, sin duda, completa y aclara lo que dice en los dos primeros pasajes citados. El tonóes muy didáctico: aclara términos, conceptos y pone una serie de ejemplos; etc. Constituye una muestra fehaciente del excepcional docente que era el Peripatético Palatino. Es tal el orden y la precisión que cualquier comentario más bien entorpece que clarifica. Tan sólo anoto que, teniendo en cuenta todos los textos abelardianos sobre la concepción de la libertad, se aprecia cómo la raíz del libre albedrío está en la racionalidad, en la inteligencia, aunque la ejecución del acto libre sea de la voluntad. Todo esto instala a nuestro autor en una visión de tipo intelectualista, alejándolo del voluntarismo. En este contexto escribe agudamente L. E. Bacigalupo: «Es interesante notar que Abelardo está preocupado por subrayar (en las tres obras citadas) el momento judicativo del animus contra una eventual primacía del elemento volitivo, como si fuera usual interpretar que el libre albedrío consiste sólo en la voluntad. Por eso podría explicarse el recurso al absurdo que le motiva tal postura [...], a saber: tener que atribuir libre arbitrio a las bestias $>{ }^{17}$.

Pasamos, ya, al apartado sobre la libertad, en que nuestro autor ostenta su mayor originalidad: las aplicaciones a grandes sectores de nuestra actividad, y las exigencias que conlleva el ser libres.

\section{Aplicaciones sobre la libertad}

He presentado la visión teórica de nuestro autor sobre la libertad. Obviamente se trata de una aportación muy fragmentaria, como es toda la construcción filosófica del siglo XII en el ámbito cristiano. Esto no le resta valor. Todo lo contrario, teniendo en cuenta las circunstancias de tiempo y lugar. Trato ahora de ciertas concreciones o aplicaciones de la libertad referidas a la conducta concreta en sectores o ámbitos vitales de especial relieve. Estimo que en este apartado es donde se aprecia con más nitidez el talante innovador, y con mayor proyección histórica, de Pedro Abelardo.

a) Libertad e investigación cientifica. No hay la menor duda de que nuestro filósofo tiene una vocación clara para la investigación intelectual. Nos dice expresamente en su autobiogra-

carent, liberum non habent arbitrium. Si quis etiam tale quid velit ac disponit facere, quod in ejus non sit potestate, vel quod sine dispositione ipsius æque fieret, in hoc liberum arbitrium non habet. Verbi gratia, sæpe talia nos facere proponimus, quæ decepti nos posse implere confidimus, et nonnunquam nitimur vel desideramus ut ea fiant, quæ non minus fierent absque nostro proposito. Veluti si qui diutinis pœenis mori cogantur, et morte ipsa cruciatus finire desiderent, et ad hoc nitantur, nequaquam, cum id accidit, ex libero suo arbitrio assequuntur; quod videlicet non minus contingeret eis etiam nibil inde præmeditantibus. Et hæc quidem liberi arbitrii definitio nullatenus in Deum cadit, sed in eos tantum qui voluntatem mutare, et in contraria possunt déflectere; ut videlicet in eorum sit potestate id quod eligitur tam dimittere quam facere. Denique et nonnulli liberum ad hoc reduxerunt arbitrium, ut his tantum ipsi concedant quæ et bene facere et male possunt. Quorum opinionem beatus quoque Hieronymus secutus Homilia illa de filio prodigo, inter cætera sic ait: 'Solus Deus est in quo peccatum non cadit; cætera, cum sint liberi arbitrii, in utrumque possunt suam deflectere voluntatem' At vero qui diligentius liberum arbitrium inspexerit, nulli benefacienti hoc deesse dixerit; maxime autem Deo, et his omnibus qui tanta beatitudine sunt corroborati, ut jam in peccatum labi non queant. Quo enim quisque a peccato remotior est, et ad bonum pronior, tanto in eligendo bonum liberius habet judicium, quanto ab illa ultima servitute peccati, de qua scriptum est: 'Qui facit peccatum, servus est peccati,' longius absistit. Generaliter itaque ac verissime liberum arbitrium dicitur, cum quilibet quod ex ratione decreverit, voluntarie ac sine coactione adimplere valebit. Quæ quidem libertas arbitrii tam Deo quam hominibus æque indubitanter inest, quicunque tunc voluntatis facultate privati non sunt, atque his præcipue, ut diximus, qui jam omnino non possunt peccare. Quamvis enim peccare nequeant, aut a bono quod faciunt minime se retrahere queant, quia non oportet, non ideo tamen id alicujus coactionis necessitate agunt, quod utique, si non vellent, nequaquam facere cogerentur. Quod et diligenter beatus attendens Augustinus, lib. XXII, De Civitate Dei, his astruit verbis: primum liberum arbitrium posse non peccare, novissimum non peccare posse»).

17 Luis E. Bacigalupo, Intención y conciencia en la Ética de Abelardo, o.c., p. 90. 
fia: «Mi tierra y mis antepasados me dieron este ágil temperamento que tengo, así como este talento para el estudio de las letras [...]. Fue tal mi pasión por aprender que dejé la pompa de la gloria militar a mis hermanos, juntamente con la herencia y la primogenitura. Abandoné el campamento de Marte para postrarme a los pies de Minervas ${ }^{18}$. Es en el campo de la investigación donde reclama con más energía la libertad, frente a las autoridades vigentes, cosa verdaderamente insólita en unos momentos en que las autoridades doctrinales tenían enorme preeminencia. El auténtico investigador no puede quedarse sin más en lo que otros han dicho, tiene que ser la razón la auténtica guía. Someterse a la luz de la razón-no resta libertad, todo lo contrario la potencia, la constituye. Esta es la libertad que requiere, exige la investigación. Sólo tiene un límite: la verdad. Pero ésta no es algo que obstaculiza y esclaviza, sino todo lo contrario; es el auténtico ámbito de la libertad del intelectual.

Recojo a continuación un primer testimonio del propio autor en que podemos apreciar con claridad su postura en lo que se refiere a la libertad del científico como tal:

«Ahora bien, toda ciencia es buena, aun la que versa sobre el mal, la cual no puede faltar al justo. Pues, para que el justo se guarde del mal, es necesario que lo conozca previamente, porque no lo evitaría si, previamente, no lo conociera. Puede ser bueno, por consiguiente, el conocimiento de aquel cuya acción es mala, como acontece que, siendo malo el pecar, es bueno, sin embargo, conocer el pecado, que de otro modo no podemos evitar.

Ni siquiera aquella ciencia, cuyo ejercicio es abominable, que se llama matemática (astrología), se ha de juzgar mala. Pues ni hay culpa en saber con qué obsequios o sacri$\because$ ficios lograrían nuestras promesas el favor de los demonios, sino en practicarlos. Ya que - si fuese malo aun saber esto, ¿cómo el mismo Dios podría ser absuelto de malicia? Él mismo, también, que contiene las ciencias de todos, pues las creó, y que solo examina las promesas de todos y hasta sus más íntimos pensamientos, conoce, ciertamente tanto lo que el diablo desearía como con qué obras podremos conseguir su aprobación.

$\mathrm{Si}$, por consiguiente, no el saber sino el actuar es malo, tampoco la malicia se ha de referir a la ciencia, sino al acto. A partir de ahí demostramos, pues, que es buena toda ciencia, la cual por solo Dios existe y procede de su generosidad. Por lo que también conviene admitir que es bueno el estudio de toda ciencia, gracias al cual se adquiere lo que es bueno; pero se ha de insistir principalmente en el estudio de aquella doctrina, de la que se conoce una verdad de mayor valor» ${ }^{19}$.

Aparece ya en la Dialectica, sin ambages, su postura sobre la libertad científica. Con la misma energía, con que critica cualquier restricción en el ámbito del conocer (sciere), recalca que no todo puede ser realizado (agere). Usando terminología de hoy: no toda aplicación técnica es posible éticamente.

18 «Historia Calamitatum», en Cartas de Abelardo y Eloisa, Alianza Editorial, Madrid, 1993, p. 38.

19 P. Abelardo, Dialectica, o.c., pp. 469-470 ( (Scientia autem omnis bona est, et ea que de malo est, que iusto deesse non potest. Ut enim iustus malum caveat, eum prenosse malum necesse est; neque enim vitaret nisi prenosceret. Cuius itaque mala est actio, bona potest esse cognitio, ut, cum malum sit peccare, bonum est tamen peccatum cognoscere, quod aliter non possumus vitare. Ea quoque scientia cuius nefarium est exercitium, que mathematica appellatur, mala putanda non est. Neque enim crimen est in sciendo quibus obsequiis aut quibus immolationibus demones nostra vota perficiant, sed in agendo. Si enim et hoc scire malum esset, quomodo ipse quoque Deus malitia absolvi posset? Ipse quoque qui omnium scientias quas creavit, continet ac solus omnium vota cogitationesque universas inspicit, scit utique et que diabolus desideret et quibus factis eius assensum consequi possimus. Si ergo scire malum non est, sed agere, nec ad scientiam sed ad actum referenda est malitia. Ex his itaque scientiam omnem, que a Deo solo est et ex ipsius munere procedit, bonam esse convincimus. Unde et omnis scientie studium bonum oportet concedi, ex quo id quod bonum est, adquiritur; eius autem doctrine studium precipue est insistendum, cuius potior veritas cognosciturn). 
Este tema es de especial interés para nuestro autor, como lo pone de manifiesto el hecho de abordarlo reiteradametne en varias obras. Repite sustancialmente las mismas ideas de la Dialectica, pero con más precisión y fundamentación, pues tanto en la Introducción a la Teología, como en la Teología Cristiana insiste en su postura. En la Introducción escribe:

«Nadie, pues, diga que existe alguna ciencia mala, ni siquiera aquella que versa sobre el mal, la cual no puede faltar al hombre justo; no para hacer el mal, sino para poder precaverse de él, una vez conocido; porque, como dice Boecio, el mal hay que conocerlo para poder evitarlo. En efecto, no es algo malo saber engañar o cometer adulterio, sino realizar esas cosas; porque incluso es bueno el conocimiento de aquello, cuya realización es pésima, nadie peca conociendo lo que es pecado, sino realizándolo. Para que fuese mala alguna ciencia, tendría que haber algo que fuese malo conocerlo. $Y$ en este caso ni el propio Dios podría estar libre del mal, porque lo conoce todo. Sólo en Él existe la plenitud del saber, y es un don suyo toda ciencia. Ciertamente la ciencia es la comprensión de todo lo que existe, $\mathrm{y}$ todo lo distingue verdaderamente [...]. De la misma manera, pues, que el conocimiento del mal es algo bueno, necesario para poder evitarlo, así también el tener capacidad de hacer el mal es bueno y necesario para merecer [hacer el bien a pesar de poder hacer el mal es meritorio] [...]. De todo esto resulta evidente que ninguna ciencia ni ningún poder es algo malo, aunque sean malas sus realizaciones, puesto que Dios es quien concede toda ciencia y todo poder ${ }^{20}$.

Es muy significativo que en todas las citas, que se refieren a la libertad científica, repita el argumento ad hominem, sin duda, dirigido a sus muchos criticos, pues la postura era muy novedosa: si fuese malo conocer algunas cosas, Dios sería el peor, pues lo conoce absolutamente todo ¿Qué podrían contestar sus adversarios?

Es tal el interés del tema que vuelve a repetir en la Teología Cristiana el mismo discurso. No aporto el texto, porque reproduce literalmente lo dicho en la Introducción ${ }^{21}$.

b) Libertad y religión. Dado que la dimensión religiosa ocupa un lugar esencial en el medievo, no es extraño que Abelardo aborde con rigor el tema, y lo analice desde distintos ángulos. Le llevó, incluso, a realizar estudios de teología después de una década ejerciendo como maestro de dialéctica. En una de sus obras de madurez, cuando ya preveía cercano el final, escribió un tratado muy interesante, en el que la libertad religiosa está presente a lo largo de todo el libro; es su famoso Diálogo entre un Filósofo, un Judio y un Cristiano ${ }^{22}$.

Fiel a su talante de intelectual que confía en la actividad racional rigurosa, toma muy en serio los descubrimientos de la razón. Plantea, así, un problema realmente vivo en su época,

20 P. Abelardo, «Introductio ad Theologiam», en Opera (cit), Vol. II, pp. 71 (líneas 33-36)-72 (líneas 1-19). ( Nemo etenim scientiam aliquam malam esse dixerit, etiam illam quæ justo homini deesse non potest. Non ut malum agat, sed ut a malo praecogitato sibi provideat, quod nisi cognitum, teste Boethio, vitare non posset. Non est enim malum scire decipere vel adulterari, sed ista committere, quia ejus rei bona est cognitio, cujus pessima est actio: et nemo peccat cognoscendo peccatum, sed committendo. Si quæ autem scientia malum esset, utique et malum esset quædam cognoscere. At jam absolvi a malitia Deus non posset, quia omnia novit. In ipso enim solo omnium est plenitudo scientiarum, cujus donum est omnis scientia. Scientia quippe est comprehensio omnium rerum quæ sunt, atque his veraciter cuncta discernit [...]. Sicut autem mali quoque scientia bona est, ad evitandum scilicet malum necessaria, ita potestatem etiam mali bonam esse constat, ad promerendum necessariam [...] Ex his itaque liquidum est nullam aut scientiam vel potestatem malam esse, quantumcunque mala sint exercitia eorum, cum et Deus tribuat omnem scientiam, et omnem ordinet potestatem [...]).

21 De todas formas remito a la obra de P. Abelardo: Theologia Christiana, en Opera (cit) Vol. II, pp. 448 (lineas 28-36) - 449 (líneas 14-15), donde puede comprobarse lo que decimos. Esta es una muestra de que la Teologia Christiana, reproduce sustancialmente la Introductión a la Teología, a veces literalmente. Pero la amplía en varios apartados.

22 Remito, especialmente, al «Prefacio» de esta obra; Ed. Yalde, Zaragoza, 1988 pp. 83-87 (Para texto latino, Opera (cit.) Vol. II, pp. 644-646). Un artículo reciente e ilustrativo sobre el Diálogo: Mariano Brasa, «Diálogo a tres bandas», Rev. Española de Filosofia Medieval, 10 (2003), 189-199. 
(y no sólo en ella): la racionalidad de los credos religiosos (Cristianismo, Judaísmo, y alguna alusión al Islamismo), ¿Cuál es el más razonable y por ello más verdadero? Pone como juez a la Ratio, e interroga, sobre todo, al cristiano y al judío. La raiz de la auténtica libertad del ser humano es también la raíz de la libertad religiosa: no es el capricho o la mera autoridad de los mayores lo que ha de movernos a un credo determinado, sino lo que el individuo humano ve como razonable, fruto de un análisis comparativo, y una reflexión sincera: he ahí el único criterio para la aceptación libre de un credo religioso. Pero oigamos al Peripatético Palatino:

«Ambos concedieron al filósofo el primer puesto en el inicio de la controversia. Dijo aquél después: Os pregunto en primer lugar a ambos algo que os concierne por igual, ya que los dos os basáis en la Escritura, a saber, si fue la reflexión racional la que os llevó a vuestros respectivos credos religiosos o si, sencillamente, os limitáis a seguir en esto la opinión de los demás hombres y el apego a vuestro pueblo. De ser cierto lo primero, ello merecería, sin duda, mi plena aprobación, mientras que de darse el segundo caso ello merecería un rechazo total. Creo, no obstante, que ningún hombre de conciencia sensaita negaria la verdad de lo segundo y menos aún si se tiene en cuenta que la abonan numerosos ejemplos [...].

Pues cada hombre abriga cierto «amor natural» por su propio pueblo y por aquellos con quienes se ha criado, de modo que todo cuanto se diga contra la fe de aquéllos le resulta odioso. Haciendo de la costumbre una segunda naturaleza, sostienen obstinadamente de adultos todo cuanto aprendieron de niños y no tieniendo capacidad para entender muchas de las cosas que se dicen, afirman creerlo. Pues, como nos recuerda el poeta: «Un vaso conservará por mucho tiempo el perfume de la primera sustancia que contuvo (Horacio. Epist. 1, 2). En este sentido argumenta, sin duda, el filósofo que dijo: «Guárdate muy bien de juzgar como sagrado todo cuanto hayas asimilado en tu aprendizaje de adolescente», pues sucede con frecuencia que un tratado de filosofia más maduro desecha aquellas cosas aptas para oídos más jóvenes. Sorprende, en efecto, que aunque el entendimiento humano se enriquezca a lo largo de las generaciones y con el transcurso del tiempo, eso pase en todos los ámbitos, pero no en lo tocante a cuestiones de fe y ello pese a que en relación con ellas amenacen los más grandes peligros. No hay progreso en este sentido, pues tanto en el caso de los jóvenes, como en el de los adultos, de los cultos como de los iletrados, puede decirse que todos ellos abrigan el mismo sentimiento respecto a la fe. Y se estima que es especialmente firme en ella aquel que no rebasa el sentido común del pueblo.

Resultado forzoso de todo ello es que a nadie se le permita inquirir entre su propio pueblo acerca de lo que debería ser creído, ni nadie puede dudar impunemente de lo que todos afirman. Pues resulta embarazoso para los hombres el que se les interrogue sobre aquello acerca de lo cual no pueden dar una respueta satisfactoria. Nadie, en efecto, que desconfie de sus propias fuerzas iniciará, espontáneamente, una disputa, y sólo aquel que espera la gloria del triunfo se lanzará voluntariamente a la batalla. Estos incurren a veces en tal locura que no se avergüenzan declarando que creen todo aquello que admiten ser incapaces de entender, como si la fe consistiera en la profesión de palabras más bien que en la comprensión de la mente y fuera más bien asunto de la boca que del corazón. De ahí que éstos se vanagloríen al máximo por el hecho de que parecen creer cosas tan excelsas que ni pueden expresar en palabras ni concebir con la mente. La adhesión de cada uno a su propio credo religioso los hace tan fatuos y orgullosos que consideran indignos de la misericordia de Dios a todos cuantos no participan de sus creencias y, juzgando así condenados a todos los demás, proclaman que sólo ellos serán dichosos» ${ }^{23}$.

23 Dialogo, o. c., pp. 88-90. Opera, cit., Vol, II, pp. 646-647. («Annuunt utrique philosopho priorem in hujus pugnæ congressu locum. Tum ille: Unde, inquit, primo vos simul interrogo, quod ad vos pariter attinere video, qui maxime scripto nitimini, utrum videlicet in has fidei sectas ratio vos induxerit aliqua, an solam hic hominum opinionem, ac generis vestri sectemini amorem, quorum quidem alterum, si sit, maxime est probandum, sicut alterum penitus improbandum. Quod tamen verum, postremum esse, nullius hominis discreti conscientiam credo negare. Ita 
La cita es un poco extensa, pero muy elocuente de la actitud abelardiana sobre la libertad religiosa. Una vez más la deslumbrante claridad y el rigor del magister resultan ejemplares. Para finalizar estas originales sugerencias, recojo otro interesantísimo testimonio de nuestro escolástico:

«EL FILÓSOFO. Ojalá pudieras, como dices, resultar tan convincente que partiendo de esa suprema sabiduría misma, a la que en griego llamáis «logos» y en latín «verbum Dei», seas capaz de mostrarte como un lógico auténtico, armado de razones que sustenten tus palabras. $Y$ no pienses que alegaré como excusa ese miserable recurso a que se:refiere vuestro Gregorio: «La fe no tiene mérito alguno para aquel a quien la razón humana le suministra una pruebay. En efecto, cuando tu pueblo no es capaz de argumentar la fe que profesa, al momento aduce esa frase gregoriana para compensar su ignorancia. Pues, en mi opinión, ¿qué otra cosa puede significar eso sino el asentir a la predicación de cualquier credo indiscriminado, sea necio o sea sensato? En efecto, si al objeto de que la fe no pierda su mérito, en modo alguno debe ser argumentada por la razón y la discusión de lo que ha de ser creído no da cabida al juicio del intelecto, sino que lo que se exige es asentir de inmediato a lo que se predica, por muchos errores que esa predicación disemine, entonces ninguna importancia tendría el aceptarlo, toda vez que allí donde no se permite el uso de la razón, ninguna refutación racional sería legítima. Pongamos que un idólatra diga esto acerca de una piedra, un leño o cualquier criatura: «aquí está el dios verdadero, creador del cielo y de la tierra» o pronuncie cualquier abominación flagrante; ¿quién podría refutarle si no ha de haber discusión racional sobre la fe? Al punto replicará a su censor, tanto más si éste es cristiano, lo que ya se dijo: «la fe no tiene mérito alguno, etc.». El cristiano quedará al punto confundido por su propia defensa, y no podrá pretender que nadie se atenga en absoluto a razones en cuestiones en que él mismo prohíbe absolutamente aducir esas razones ni tampoco podrá justificadamente atacar a nadie argumentando atinadamente en materia de fe, ya que él no permite a nadie que le ataque en lo más mínimo con argumentos racionales» ${ }^{24}$.

namque singulis hominibus proprii generis et eorum cum quibus educantur, insitus est amor, ut contra eorum fidem quicquid dicatur, abhorreant; et consuetudinem in naturam vertentes, quicquid didicerunt pium pueri, obnixe tenent adulti, et antequam ea quæ discuntur, capere valeant, credere se affirmant, ut enim et poeta meminit, "quo semel est imbuta recens, servabit odorem testa diu'. Quales quidem philosophorum quidam arguit, dicens: 'Neve, si quid in puerilibus disciplinis acceperint, id sacro sanctum judicetur! Quoniam quidem res teneris auribus accommodatas sæpe philosophiæ senior tractatus eliminat'. Quid enim? mirabile est, cum per æatum seriem et temporum successionem, humana in cunctis rebus creatis intelligentia crescat, in fide cujus errori summum periculum imminet, nullus est profectus? Sed æque minores ut majores, æque rustici ut litterati de hac sentire asseruntur, et ille firmissimus in fide dicitur, qui communem populi non excedit sensum. Quod profecto ideo certum est accidere, quod nemini apud suos quid sit credendum licet inquirere, nec de his quæ ab omnibus dicuntur impune dubitare. Pudet namque homines de his se interrogari, de quibus respondere non sufficiunt. Nemo quippe libenter accedit, qui de propriis viribus diffidit, et ultroneus currit ad pugnam, qui victoriæ sperat gloriam. Hi etiam in tantam sæpe prorumpunt insaniam, ut quod se non posse intelligere confitentur, credere se profiteri non erubescant, quasi in prolatione verborum potius quam in comprehensione animi fides consistat, et oris ipsa sit magis quam cordis. Qui hinc quo maxime gloriantur, cum tanta credere videantur, quæ nec ore disseri nec mente concipi valeant. Quos etiam adeo præsumptuosos et elatos facit propriæ sectæ singularitas, ut quoscunque a se viderïnt in fide divisos, a misericordia Dei alienos, et omnibus aliis condemnatis, solos se prædicent beatosn).

24 P. Abelardo, Diálogo, o.c., pp. 141-142. — Gregorio: Se refiere a Gregorio Magno, Papa (590-604)-, Opera, cit, Vol. II, pp. 671-672. («PHILOS: Ad quæ utinam, ut dicis, sic convincere possis, ut ab ipsa, ut dicitis, suprema sapientia, quam Grace.logon, latine verbum Dei vocatis, vos vere logicos et verborum rationibus exhibeatis esse armatos. Nec illud Gregorii vestri me miserum refugium prætendere præsumatis. 'Fides, inquit, non habet meritum, cui ratio humana præbet experimentum'. Quia enim apud vos fidem, quam astruunt, disserere non sufficiunt, statim ad suæ imperitiæ solatium hoc Greforianum assumunt. Quod quidem juxta eorum opinionem quid aliud agit, nisi ut quibuslibet fidei prædicationibus æque stultis sicus et sanis acquiescamus? Si enim fides ratione minime sit discutienda, ne meritum amittat, nec quid credi oporteat animi judicio sit discutiendum, sed statim his quæ prædicantur, assentiendum, quoscunque errores prædicatio seminet, suscipere nihil refert, quia nihil licet ratione refellere, ubi rationem non licet adhibere. Dicat idolatria de lapide vel ligno vel qualibet creatura: Hic est Deus verus 
De todo lo dicho se desprende que Pedro Abelardo es uno de los moderni del siglo XII que sigue la consigna que entonces se imponían a sí mismos: estar abiertos al presente y al futuro, pero tener también un conocimiento riguroso del pasado. Desde estas premisas elabora un pensamiento muy original: todo lo que aborda lo transforma y enriquece. Esto, una vez más, se confirma en el tema de la libertad.

César Raña Dafonte darace@mixmail.com

creator coeli et terræ; vel quamlibet patentem abominationem prædicet, quis eum valebit refellere, si de fide nihil sit discutiendum ratione? Statim arguenti se et maxime christiano et quod præmissum est objicit, "Fides non habet meritum, etc.' Statim christianus ex ipsa sua defensione confundetur, dicens ejus penitus rationes in talibus audiendas non esse, ubi eas ipse penitus induci prohibet, nec eum aliquem rationibus de fide recte impugnari minime permittit»). 